\title{
EFEITOS DE RESTOS CULTURAIS DE MILHO SOBRE O CRESCIMENTO DE PLANTAS DE CAFEEIRO (Coffea arabica L.)
}

\begin{abstract}
RESUMO - Com esta pesquisa visou-se a testar o efeito de restos culturais da parte aérea de três cultivares de milho sobre o crescimento de plântulas de cafeeiro, cv. Rubi, em condições de casa-de-vegetação, na Universidade Federal de Lavras, Lavras - Minas Gerais. Os tratamentos foram constituídos de $0,2,4$ e $8 \mathrm{t} \mathrm{ha}^{-1}$ de palhada de milho (cv. AG1051, C333 e C435), incorporada ou em cobertura, em vasos de $8 \mathrm{~L}$ de capacidade preenchidos com solo. Avaliaram-se a área foliar, altura e diâmetro de caule das plantas de café aos 60, 120 e 180 dias após o plantio (DAP), o teor de clorofila aos
\end{abstract}

\author{
CLÁUDIO COSTA DOS SANTOS ${ }^{1}$ \\ ITAMAR FERREIRA DE SOUZA
IS WAGNER RODRIGUES ALVES \\ ITAMAR FERREIRA DE SOUZA
LUIS WAGNER RODRIGUES ALVES
}

170 DAP e a biomassa seca de raízes aos 180 DAP. A palhada de milho incorporada ao solo causou redução na área foliar, na altura e no diâmetro de caule até os 60 DAP. A palhada da cultivar AG1051 ocasionou maiores efeitos negativos sobre o crescimento das plantas de cafeeiro, quando incorporada. $\mathrm{O}$ uso de palhada de milho em cobertura promoveu aumento de todas as características estudadas, com exceção do teor de clorofila. A palhada da cultivar C435 em cobertura do solo foi a que mais estimulou o crescimento das plantas.

TERMOS PARA INDEXAÇÃO: Alelopatia, milho, café, coffea.

\section{CORN RESIDUES EFFECTS ON COFFEE (Coffea arabica L.) PLANTS GROWTH}

\begin{abstract}
The objective of this research was to verify the effect of three corn cultivars residues, on coffee plants, cv. Rubi, under greenhouse conditions, at Lavras Agricultural University, Lavras, Minas Gerais State, Brazil. The treatments were zero, 2, 4 and $8 \mathrm{t}$ $\mathrm{ha}^{-1}$ of corn residues (cv. AG1051, C333 and C435) either incorporated or on the top of $8 \mathrm{~L}$ pots filled with soil. Leaf area, plant height and stem diameter of coffee plants were taken at 60, 120 and 180 days after planting (DAP); at 170 DAP chlorophyll
\end{abstract}

INDEX TERMS: Allelopathy, corn, coffee.

\section{INTRODUÇÃO}

Os efeitos benéficos e negativos do sistema de rotação e sucessão de culturas vêm sendo explicados, em parte, pelo fenômeno da alelopatia, que se refere às interações bioquímicas entre os organismos de uma mesma comunidade. A interferência entre plantas, nesse caso, se processa por meio de compostos (aleloquí- content was determined and at 180 DAP roots were harvested. Incorporated corn residues promoted reduction on leaf area, plant height and stem diameter at 60 DAP. The AG1051 cultivar corn residues showed strongest inhibitory effects on coffee plants when incorporated in soil, while C435 stimulated coffee growth when applied on top of the soil, except for chlorophyll content which was not altered when compared with no corn residues treatment.

1. Engenheiro Agrônomo, MS, EPAMIG, Caixa Postal 176, Lavras, MG, 37200-000 - csantoscosta@bol.com.br

2. Engenheiro Agrônomo, PhD, UNIVERSIDADE FEDERAL DE LAVRAS/UFLA, Caixa Postal 37, Lavras, MG, 37200-000.

3. Engenheiro Agrônomo, MS, UNIFENAS, Caixa Postal 23, Alfenas, MG, 37130-000. 
(ALTIERI e DOLL, 1978), milho (ANDERSON e CRUSE, 1995; ALMEZORI et al., 1999) e alface (Lactuca sativa L.) (SANTOS et al., 2001). Os restos dessa cultura contêm substâncias alelopáticas com propriedades reguladoras de crescimento que reduzem a germinação, o crescimento de raízes e as brotações de plântulas, e a intensidade de tais efeitos depende do material de origem, de sua incorporação ou não ao solo (DURIGAN e ALMEIDA, 1993) e pode persistir por período de até 22 semanas (GUENZI e MCCALLA 1966b; ALMEZORI et al., 1999). Diversos compostos secundários (ácidos hidroxâmicos, ácido fenil-acético, fenil-butírico, Ohidroxifenilacético, p-cumárico, siríngico, vanílico, ferúlico e p-hidroxibenzóico) são produzidos nas folhas, raízes e pólen de plantas de milho e apresentam efeitos negativos. Brassinosteróides, flavonóides e $\beta$-carotenos também têm sido reportados como prejudiciais (GUENZI e MCCALLA, 1966a; ARGANDOÑA e CORCUERA,1985; SUZUKI et al.; 1986, CESKA e STYLES, 1984, SICKER et al., 2001). Souza e Einhellig (1994) observaram que a benzoxazolinona, um aleloquímico produzido pelo milho, causou redução no teor de clorofila de lentilha d'água (Lemna minor L.), prejudicando a fotossíntese. Restos culturais incorporados ao solo também inibem a absorção de nutrientes ou reduzem a nitrificação por meio de alguns aleloquímicos ou causam imobilização de nitrogênio pela ação de microrganismo (RICE, 1984).

Souza et al. (2000) observaram que a palha do capim-braquiária (Brachiaria decumbens Stapf.) incorporada ao solo a $3 \%(\mathrm{p} / \mathrm{p})$ reduziu a síntese de clorofila nas variedades de cafeeiro Mundo Novo e Icatu, porém, sem afetar a variedade Obatã. (Edinaldo José Abrahão, comunicação pessoal EMATER-Lavras, MG, 2000), em observações de campo, verificou acentuada redução de desenvolvimento de plantas de cafeeiro, quando plantadas em sucessão à cultura do milho sem qualquer causa evidente, o que poderia ser causada pelo potencial alelopático de restos culturais do milho.

Objetivou-se com este trabalho identificar, em casa-de-vegetação, os efeitos que os restos culturais do milho podem exercer sobre o crescimento inicial de plantas de cafeeiro.

\section{MATERIAL E MÉTODOS}

Este trabalho fez parte de uma linha de pesquisa sobre potencial alelopático da cultura do milho sobre plantas de cafeeiro, sendo este experimento conduzido no período de março a setembro de 2001, em casa-de-vegetação, no Departamento de Agricultura da Universidade Federal de Lavras (UFLA). O delineamento experimental foi o de blocos casualizados, com quatro repetições. Os tratamentos foram dispostos em esquema fatorial $3 \times 3 \times 2+1$, sendo os fatores: restos culturais da parte aérea de milho (palhada) das cultivares AG1051, C333 e C435, aplicados em três níveis $\left(2,4\right.$ e $\left.8 \mathrm{t} \mathrm{ha}^{-1}\right)$; duas formas de aplicação (com e sem incorporação) ao solo, mais uma testemunha sem palhada. Cada parcela constituiu-se de uma planta de cafeeiro, cv. Rubi, plantada em vaso de 8 litros de capacidade, preenchido com 7 $\mathrm{kg}$ de solo de superfície (Latossolo Vermelhoamarelo eutrófico, textura argilosa), cujos resultados das análises física e química podem ser observados na Tabela 1. Esse solo foi coletado em área adjacente a um experimento de campo, instalado com os mesmos objetivos, onde foi semeado milho em novembro de 2000. Desse experimento de campo, coletou-se a parte aérea das plantas (por ocasião do florescimento: pendoamento), que foram picadas em fragmentos com aproximadamente um centímetro de comprimento e secas em estufa com circulação forçada de ar a $50^{\circ} \mathrm{C}$, até peso constante.

Aos vasos, adicionaram-se $\mathrm{P}_{2} \mathrm{O}_{5}$ e $\mathrm{K}_{2} \mathrm{O}$ em quantidades proporcionais àquelas recomendadas para adubação de plantio em cova . As palhadas de milho foram colocadas nos vasos nas proporções de 2,4 e 8 toneladas por hectare, aplicadas sobre a superfície ou incorporadas homogeneamente em toda profundidade (20 $\mathrm{cm})$ do solo nos vasos. Adotaram-se como critério para cálculo de área dos vasos os diâmetros médios entre as superfícies superior e inferior dos mesmos.

Irrigações foram realizadas sempre que necessário, visando a manter a umidade do solo próxima à capacidade de campo. Em intervalos de 45 dias, realizaram-se adubações foliares com ácido bórico e sulfato de zinco a $0,1 \%(\mathrm{p} / \mathrm{v})$ (MATIELLO, 1991), $10 \mathrm{~g}$ de cloreto de potássio e $10 \mathrm{~g}$ de sulfato de amônio em cobertura por vaso (GUIMARÃES e MENDES, 1998). 
TABELA 1 - Dados de análise física e química do solo utilizado no experimento de efeito de restos culturais de milho sobre o crescimento de plantas de cafeeiro. Lavras, MG, 2001.

\begin{tabular}{|c|c|c|c|c|c|c|c|c|c|c|c|c|}
\hline \multicolumn{13}{|c|}{ Análise física $\left(\mathrm{dag} \mathrm{kg}^{-1}\right)$} \\
\hline \multicolumn{4}{|c|}{ Areia } & \multicolumn{6}{|c|}{ Silte } & \multicolumn{3}{|c|}{ Argila } \\
\hline \multicolumn{4}{|c|}{30} & \multicolumn{6}{|c|}{22} & \multicolumn{3}{|c|}{48} \\
\hline \multicolumn{13}{|c|}{ Análise química } \\
\hline $\mathrm{pH}$ & $\mathrm{P}$ & $\mathrm{K}$ & $\mathrm{Ca}^{2+}$ & $\mathrm{Mg}^{2+}$ & $\mathrm{Al}^{3+}$ & $\mathrm{H}+\mathrm{Al}$ & SB & $\mathrm{t}$ & $\mathrm{T}$ & V & $\mathrm{m}$ & Mo \\
\hline Água & $\mathrm{mg} \mathrm{dm}^{-3}$ & $\ldots$ & $\ldots . . \mathrm{cm}$ & $\mathrm{dm}^{-3} \ldots$ & ...... & $\ldots \ldots \ldots$ & $\ldots \mathrm{cm}$ & $m^{-3}$. & & ....... & ..... & dag $\mathrm{kg}^{-1}$ \\
\hline 5,9 & 3,1 & 67 & 2,8 & 2,7 & 0 & 2,3 & 5,7 & 5,7 & 8 & 71,1 & 0 & 2,4 \\
\hline
\end{tabular}

Aos 7 dias após o plantio (DAP), mediu-se a altura das plantas, tomada do colo até a gema apical, utilizando régua graduada em milímetro. O diâmetro de caule foi medido ao nível do solo, em milímetros, utilizando paquímetro. A área foliar foi medida com régua e estimada pela fórmula $(\mathrm{A}=$ comprimento $\mathrm{x}$ largura x 0,667 x 2), proposta por Barros et al. (1973). A área foliar acumulada em centímetros quadrados, altura acumulada em centímetros e o diâmetro de caule acumulado em milímetros foram avaliados aos 60, 120 e 180 DAP. Essas variáveis foram determinadas pela diferença entre a medida obtida em cada data e a medida tomada aos 7 DAP. Aos 170 DAP, determinou-se o teor de clorofila, quando se retirou uma folha completamente expandida, localizada entre o terceiro e quinto nó a partir do ápice de um ramo (porção mediana da planta), que foi imediatamente envolvida em papel-alumínio e colocada em caixa de isopor com gelo. A quantificação das clorofilas a, b e total foi realizada segundo o método proposto por Arnon (1949). Ao final do período experimental (180 DAP) as plantas foram removidas dos vasos para determinação de biomassa seca de raízes.

Aos dados, foram aplicadas análises de variância, contraste de médias pelo teste $\mathrm{t}$ a $5 \%$ de probabilidade e análise de regressão.

\section{RESULTADOS E DISCUSSÃO}

A palhada de milho incorporada ao solo causou redução na área foliar acumulada em relação à testemunha em 20,6\% até 60 DAP (Figura 1). Esse efeito pode ser devido à liberação de aleloquímicos pela palhada em decomposição (RICE, 1984) ou i- mobilização de $\mathrm{N}$ pelos microrganismos do solo, causado pela alta relação $\mathrm{C} / \mathrm{N}$ do material (RAIJ, 1991; PAVINATO et al., 1994). Tal período de inibição corrobora com as observações de Guenzi et al. (1967) e Almezori et al. (1999), que constataram efeito inibitório de ácidos fenólicos da palhada de milho sobre o crescimento da parte aérea de plântulas de trigo e milho por 22 e 6 semanas, respectivamente. Aos 120 e 180 DAP, não se verificou efeito da palhada incorporada em relação à testemunha, possivelmente devido à liberação de nitrogênio resultante da decomposição da palhada ou decomposição rápida de aleloquímicos em decorrência da incorporação ao solo. Nessas datas, a palhada em cobertura provocou acréscimos de $34,9 \%$ e $45,3 \%$, respectivamente, provavelmente em função de seu efeito físico de cobertura do solo.

Pela Figura 2, observou-se, aos 180 DAP, efeito dos níveis de palhada aplicada na superfície do solo, e $2 \mathrm{t} \mathrm{ha}^{-1}, 4 \mathrm{t} \mathrm{ha}^{-1}$ e $8 \mathrm{t} \mathrm{ha}^{-1}$ causaram aumentos de $24,5 \%, 44,0 \%$ e $67,4 \%$, respectivamente, na área foliar acumulada em relação à testemunha. Para cada tonelada de palhada adicionada em cobertura por hectare, a estimativa de aumento de área foliar foi de $70 \mathrm{~cm}^{2}$, apenas aos $180 \mathrm{DAP}$ (Figura 3).

De acordo com Durigan e Almeida (1993), restos culturais em cobertura liberam, de forma lenta e contínua, quantidades de aleloquímicos com efeitos negativos sobre outras plantas. No entanto, constatou-se efeito benéfico causado, possivelmente, por propriedades físicas da palhada em cobertura, que possibilitou maior retenção de umidade e menor variação de temperatura no solo. Além disso, aleloquímicos, quando liberados em quantidades muito 
pequenas, podem também ocasionar efeitos benéficos (GUENZI e MCCALLA, 1966b).

Da mesma forma que a área foliar, a altura de plantas aos 60 DAP foi $24 \%$ menor na presença de palhada de milho incorporado. As palhadas aplicadas na superfície provocaram aumento de $26,0 \%, 36,5 \%$ e $37 \%$ em relação à testemunha aos 60,120 e 180
DAP, respectivamente (Figura 4). Para cada tonelada de palhada de milho que se adicionou em cobertura por hectare, a estimativa de aumento na altura acumulada por planta foi de $0,38 \mathrm{~cm}$ e $0,56 \mathrm{~cm}$ aos 120 e 180 DAP, respectivamente (Figura 5). Não se observou efeito para quantidade de palhada aos 60 DAP.
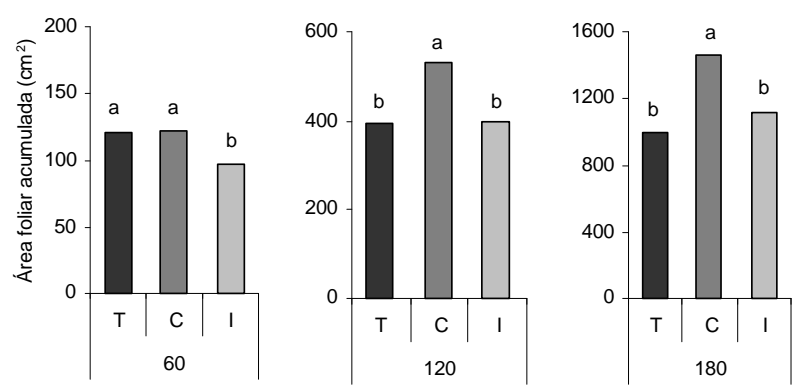

Dias após o plantio

Grupo de colunas com as mesmas letras são significativamente iguais entre si pelo teste t a 5\% de probabilidade. C: palhada de milho em cobertura; I: palhada incorporada; T: testemunha.

FIGURA 1 - Área foliar acumulada de plantas de cafeeiro cv. Rubi, aos 60, 120 e 180 DAP, em função da forma de aplicação da palhada de milho ao solo. Lavras, MG, 2001.
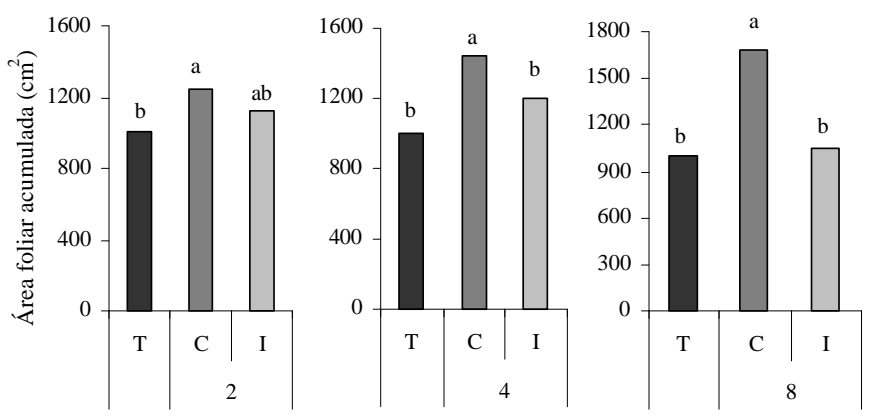

Quantidade de palhada $\left(\mathrm{t} \mathrm{ha}^{-1}\right)$

Grupo de colunas com as mesmas letras são significativamente iguais entre si pelo teste $\mathrm{t}$ a $5 \%$ de probabilidade. C: palhada de milho em cobertura; I: palhada incorporada; T: testemunha.

FIGURA 2 - Área foliar acumulada de plantas de cafeeiro cv. Rubi, aos 180 DAP, em função da quantidade e forma de aplicação da palhada de milho ao solo. Lavras, MG, 2001. 


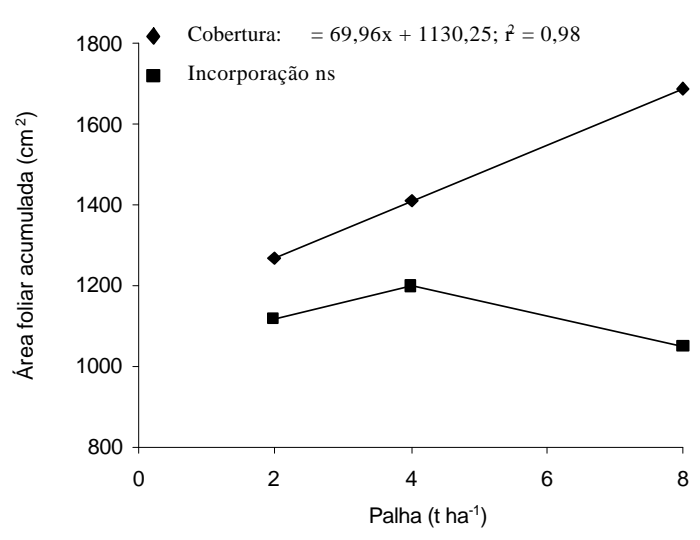

FIGURA 3 - Regressão de área foliar acumulada de plantas de cafeeiro cv. Rubi, aos 180 DAP, em função da forma de aplicação da palhada de milho ao solo. Lavras, MG. 2001.
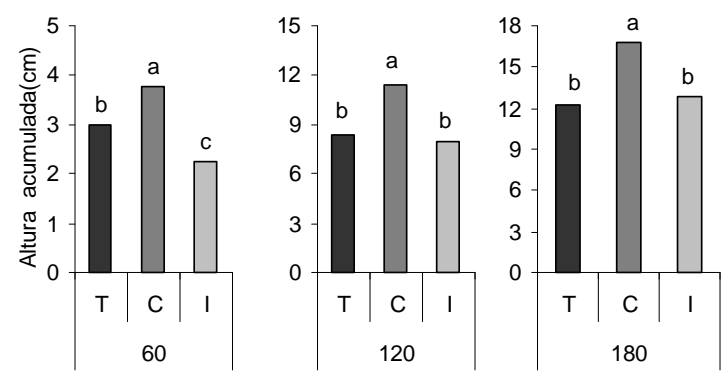

Dias após o plantio

Grupo de colunas com as mesmas letras são significativamente iguais entre si pelo teste $\mathrm{t}$ a $5 \%$ de probabilidade. C: palhada de milho em cobertura; I: palhada incorporada; T: testemunha.

FIGURA 4 - Altura acumulada de plantas de cafeeiro cv. Rubi, aos 60, 120 e 180 DAP, em função da forma de aplicação da palhada de milho ao solo. Lavras, MG, 2001.

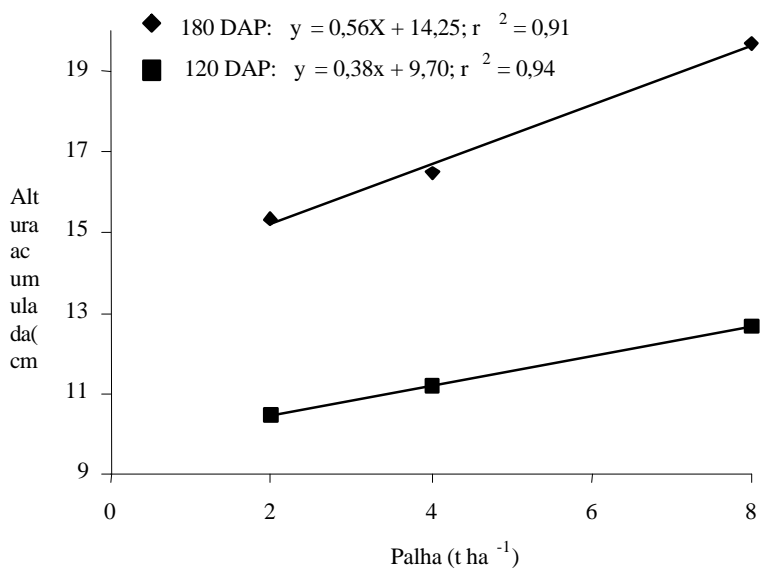

FIGURA 5 - Regressão de altura acumulada de plantas de cafeeiro cv. Rubi, aos 120 e 180 DAP, em função da quantidade e aplicação de palhada de milho em cobertura do solo. Lavras, MG, 2001. 

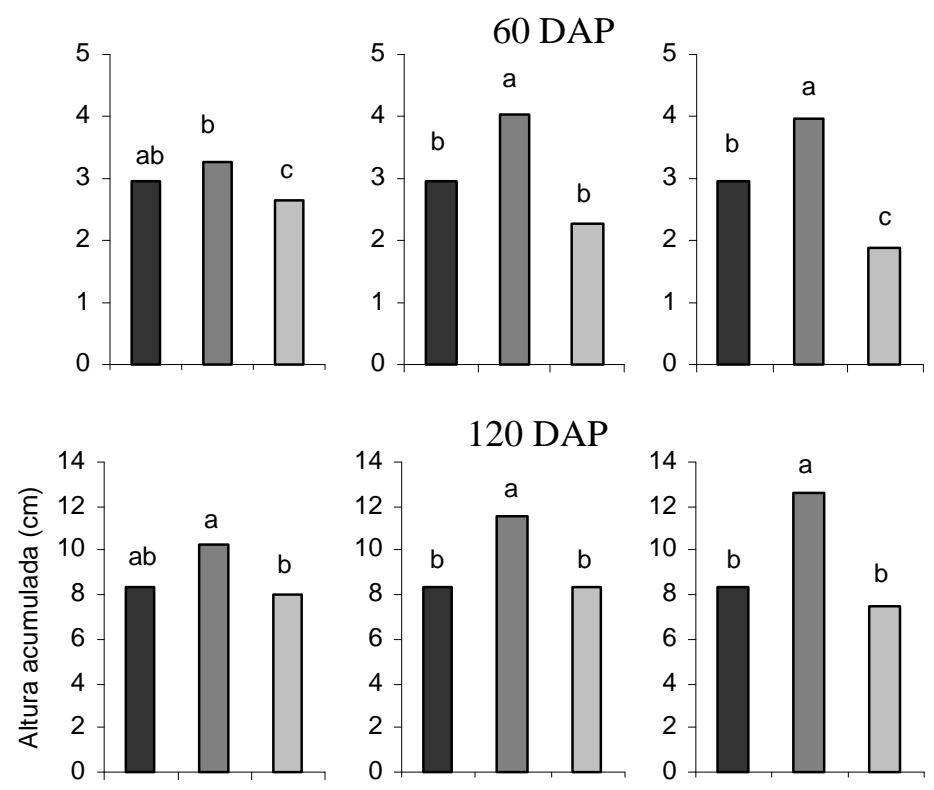

180 DAP
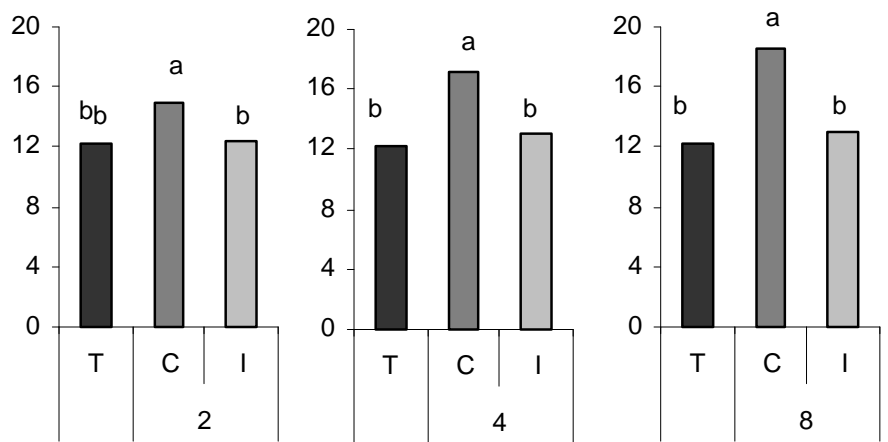

Quantidade de palhada $\left(\mathrm{t} \mathrm{ha}^{-1}\right)$

Grupo de colunas com as mesmas letras são significativamente iguais entre si pelo teste $\mathrm{t}$ a $5 \%$ de probabilidade. C: palhada de milho em cobertura; I: palhada incorporada. T: testemunha.

FIGURA 6 - Altura acumulada de plantas de cafeeiro cv. Rubi, aos 60, 120 e 180 DAP, em função da forma de aplicação dentro de cada nível de palhada de milho ao solo. Lavras, MG, 2001.

Observou-se pela Figura 6 que a palhada incorporada na quantidade $8 \mathrm{t} \mathrm{ha}^{-1}$ provocou redução de $38,5 \%$ na altura de plantas aos 60 DAP, com recuperação aos 120 e 180 DAP. Esse período de inibição do crescimento em altura se enquadra dentro das épocas de 22 ou 6 semanas de persistência de efeitos negativos verificados por Guenzi et al. (1967) e Almezori et al. (1999), respectivamente. Aos 180 DAP, a palhada aplicada em cobertura, nas quantidades $2 \mathrm{t} \mathrm{ha}^{-1}, 4 \mathrm{tha}^{-1}$ e $8 \mathrm{t}$ $\mathrm{ha}^{-1}$, ocasionou aumentos na altura acumulada de
$22,2 \%, 39,4 \%$ e $51,2 \%$, respectivamente, em relação à testemunha.

Aos 60 DAP, o crescimento em diâmetro de caule das plantas de cafeeiro foi reduzido em 15,7\% na presença de palhada incorporada em relação à testemunha que, por sua vez, não diferiu significativamente da palhada em cobertura (Figura 7). Esse período de ocorrência de efeitos inibitórios concorda mais uma vez com as observações de Guenzi et al. (1967) e Almezori et al. (1999). 

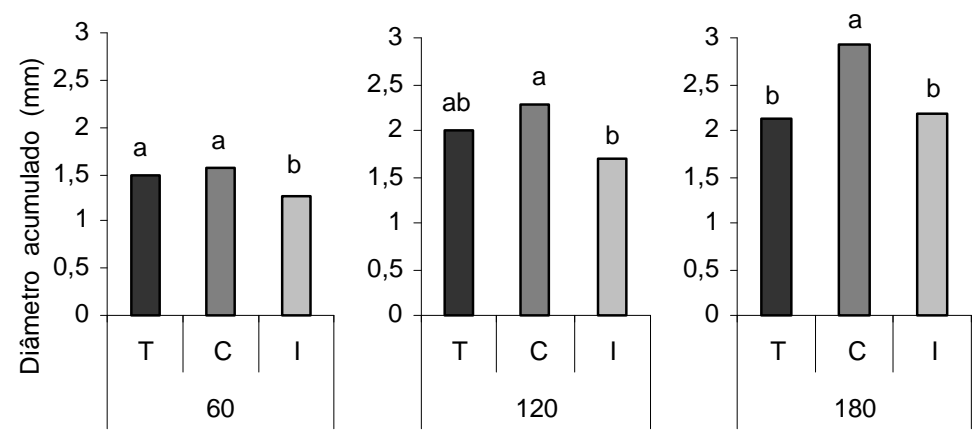

Dias após o plantio

Grupo de colunas com as mesmas letras são significativamente iguais entre si pelo teste t a 5\% de probabilidade. C: palhada de milho em cobertura; I: palhada incorporada; T: testemunha.

FIGURA 7 - Diâmetro de caule acumulado de planta de cafeeiro cv. Rubi, em função forma de aplicação de palhada de milho no solo. Lavras, MG, 2001.

Na presença da palhada em cobertura, o crescimento em diâmetro de caule, aos 120 DAP, foi 34,4\% maior em relação à palhada incorporada ao solo. Constatou-se, aos 180 DAP, que a utilização de palhada em cobertura proporcionou crescimento em diâmetro $36,9 \%$ maior do que a testemunha e que a palhada incorporada.

Aos 180 DAP, a biomassa seca de raízes de cafeeiro aumentou na presença da palhada de milho em cobertura. A variedade C435 causou maior incremento de biomassa seca de raízes quando aplicada a 2 e $4 \mathrm{t} \mathrm{ha}^{-1}$, ao passo que a $8 \mathrm{t} \mathrm{ha}^{-1}$, as cultivares AG1051 e C333 estimularam mais a produção de biomassa. Isso indica, possivelmente, a ação diferenciada da composição de aleloquímicos entre a cultivar C435 e as cultivares AG1051 e C333. A palhada da cultivar C333, quando incorporada a 2 e $4 \mathrm{t} \mathrm{ha}^{-1}$, causou aumentos de $16,3 \%$ e $29,5 \%$, respectivamente. $\mathrm{Na}$ quantidade $8 \mathrm{t} \mathrm{ha}^{-1}$, a palhada da cultivar AG1051 causou redução de $14 \%$ na biomassa seca de raízes (Figura 8).

Observou-se que, aos 180 DAP, a palhada em cobertura do solo mostrou-se significativamente superior à testemunha e à palhada em incorporação, nas diferentes quantidades aplicadas, causando maior acúmulo de biomassa seca de raízes. A palhada da cultivar C435, incorporada na quantidade $2 \mathrm{t}$ ha ', ao contrário da 'AG1051' e 'C333' em incorporação, causou estímulo (Figura 9). Segundo Guenzi e
McCalla, (1966b) pequenas quantidades de alguns aleloquímicos podem estimular o crescimento de plantas.

As cultivares AG1051 e C333 promoveram acréscimos estimados em 0,14 e 0,18 gramas por planta na biomassa seca de raiz de cafeeiro, respectivamente, aos 180 DAP, para cada tonelada de palhada de milho aplicada por hectare em cobertura. Por outro lado, a cultivar AG1051 proporcionou decréscimo de 0,11 grama de biomassa seca de raízes, por planta, para cada tonelada de palhada incorporada por hectare (Figura 10). As diferentes quantidades da palhada da cultivar C435 em cobertura e das cultivares C333 e C435 incorporadas não apresentaram efeitos significativos.

As palhadas de milho cv. AG1051, C333 e C435 não afetaram o teor de clorofila das plantas de cafeeiro cv. Rubi, embora se saiba que essa espécie pode sofrer alterações na síntese desse pigmento por interferência alelopática (SOUZA et al., 2000), e que o milho produz aleloquímico (benzoxazolinona) capaz de inibir a síntese de clorofila (SOUZA e EINHELLIG, 1994). A ausência de efeito inibitório da palhada de milho sobre o teor de clorofila nesta pesquisa poderia ser atribuída à tolerância da cultivar Rubi ou à decomposição do aleloquímico, seguida de recuperação das plantas, uma vez que a avaliação foi realizada aos 170 DAP. 
Palhada em cobertura

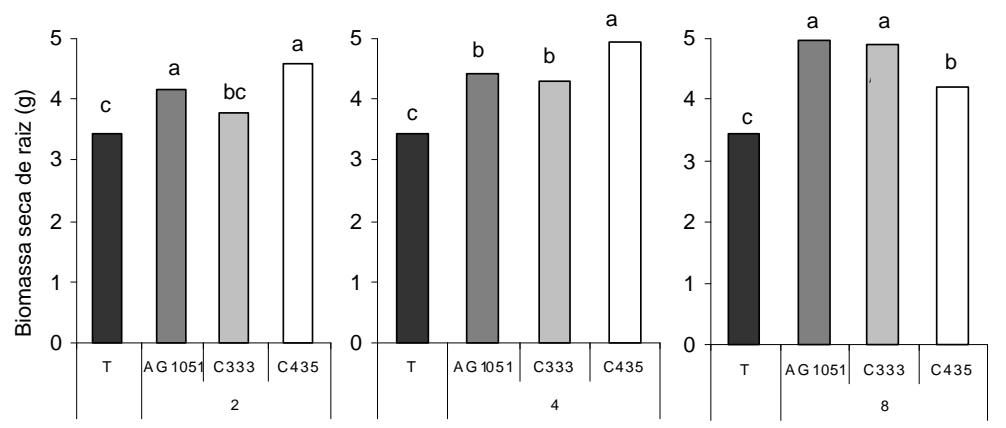

Palhada incorporada

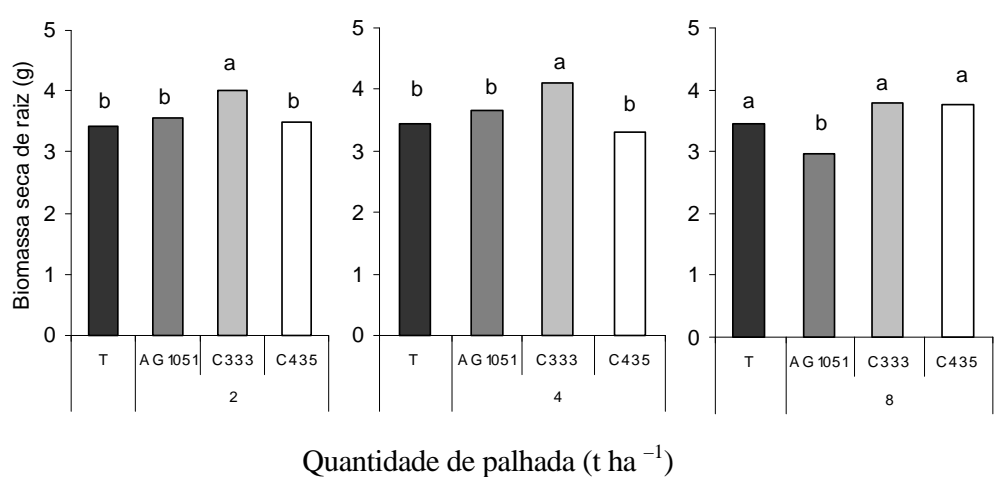

Grupo de colunas com as mesmas letras são significativamente iguais entre si pelo teste t a 5\% de probabilidade. T: testemunha.

FIGURA 8 - Biomassa seca de raízes de plantas de cafeeiro cv. Rubi, aos 180 DAP, em função da quantidade e tipo de palhada de milho aplicada ao solo. Lavras, MG, 2001. 

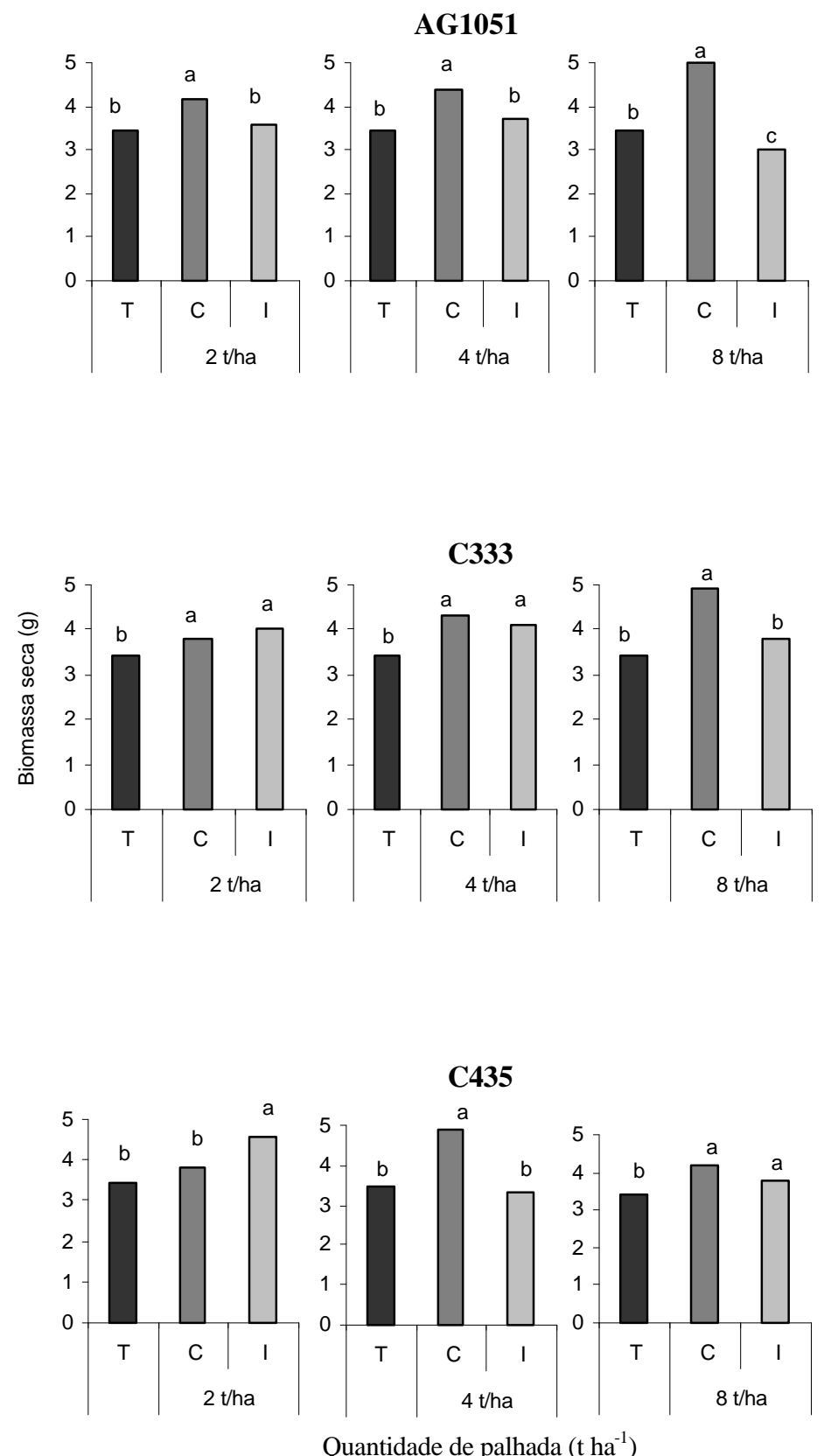

Colunas com as mesmas letras são significativamente iguais entre si pelo teste t a $5 \%$ de probabilidade. C: palhada de milho em cobertura; I: palhada incorporada; T: testemunha.

FIGURA 9 - Biomassa seca de raízes de plantas de cafeeiro cv. Rubi, aos 180 DAP, em função da quantidade, cultivar e forma de aplicação da palhada de milho ao solo. Lavras, MG, 2001. 
Palhada em cobertura

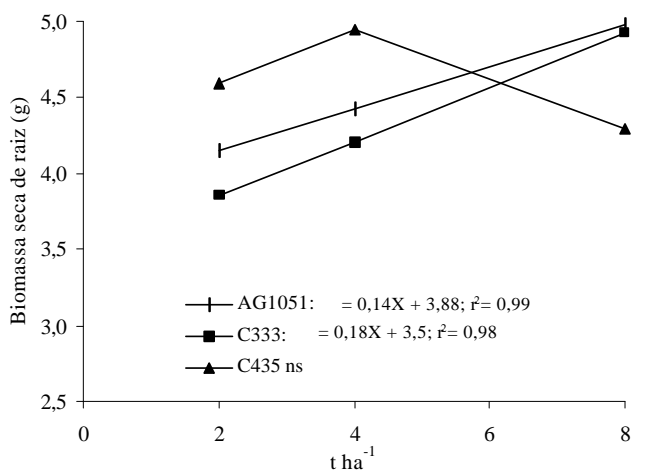

Palhada incorporada

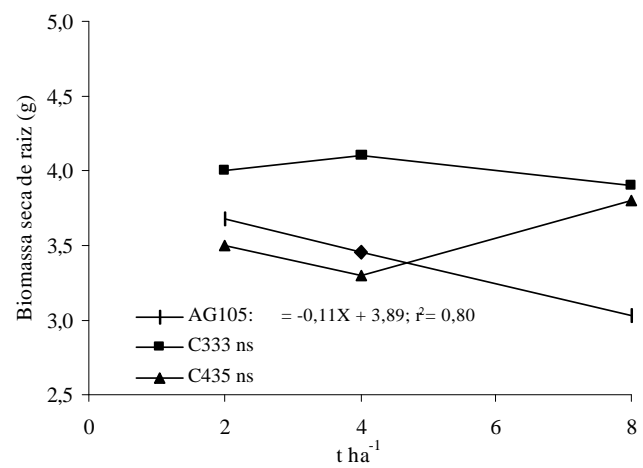

FIGURA 10 - Regressão de biomassa seca de raízes de plantas de cafeeiro cv. Rubi, em função da cultivar, quantidade e forma de aplicação da palhada de milho ao solo. Lavras, MG, 2001.

\section{CONCLUSÕES}

Conclui-se, pelos resultados, que a área foliar, altura de planta e diâmetro de caule de plantas de cafeeiro cv. Rubi foram afetados negativamente pela palhada de milho (cultivares AG1051, C333 e C435) incorporadas ao solo até 60 DAP. Aos 120 e 180 DAP, houve efeito apenas da palhada em cobertura, que, ao contrário, promoveu aumento dessas variáveis, à medida que se aumentou a quantidade. A biomassa seca de raízes foi menor na presença da palhada de milho cv. AG1051 incorporada ao solo, aos 180 DAP, ao passo que as palhadas das cultivares AG1051 e C333 em cobertura do solo causaram aumento dessa característica. O teor de clorofila não foi afetado pela palhada das cultivares de milho aos 170 DAP.

\section{AGRADECIMENTOS}

Aos Drs. Rubens José Guimarães, Carlos Alberto Spaggiari Souza, do Departamento de Agricultura da Universidade Federal de Lavras e ao Dr. Edinaldo José Abrahão, da EMATER-Lavras, MG, pelos valiosos subsídios que possibilitaram a realização deste trabalho.

\section{REFERÊNCIAS BIBLIOGRÁFICAS}

ALMEIDA, F. S. Controle de plantas daninhas em plantio direto. Londrina: IAPAR, 1991. 34 p. (IAPAR - Circular Técnica, n. 67).

ALMEZORI, H. A.; AL-SAADAWI, I. S.; ALHADITHI, R. T. Allelopathic effects of corn residues on the subsequent corn crop. Allelopathy Journal, Hisar, v. 6, n. 2, p. 193-200, 1999.
ALTIERI, M. A; DOLL, J. D. The potential of allelopathy as a tool for weed management in crop fields. PANS, London, v. 24, n. 4, p. 495-502, Dec. 1978.

ANDERSON, I. C.; CRUSE, R. M. Tillage and allelopathic aspects of the corn-soybean rotation effect. Washington: American Chemical Society, 1995. p. 184-192.

ARGANDOÑA, V. H.; CORCUERA, L. J. Distribution of hidroxamic acids in Zea mays tissues. Phytochemistry, Oxford, v. 24, n. 1, p. 177- 178, 1985.

ARNON, D. I. Cooper enzymes in isolates chloroplasts. Polyphenoloxidase in Beta vulgaris. Plant Physiology, Maryland, v. 24, n. 1, p. 1-15, Jan./Mar. 1949.

BARROS, R. S.; MAESTRI, M.; VIEIRA, M.; BRAGA FILHO, L. J. Determinação de área de folhas do café (Coffea arabica cv. Bourbon Amarelo). Revista Ceres, Viçosa, v. 20, n. 107, p. 44-52, jan. 1973.

CESKA, O.; STYLES, E. D. Flavonoides from Zea mays pollen. Phytochemistry, Oxford, v. 23, n. 8, p. 1822-1823, 1984.

DURIGAN, J. C.; ALMEIDA, F. L. S. Noções sobre alelopatia. Jaboticabal: FUNEP, 1993. 28 p.

GUENZI, W. D.; MCCALLA, T. M. Inhibition of germination and seedling development by crop residues. Soil Science Society America Proceedings, Madison, v. 26, p. 456-458, 1962. 
GUENZI, W. D.; MCCALLA, T. M. Phenolic acids in oats, wheat, sorghum, and corn residues and their phytotoxicity. Agronomy Journal, Madison, v. 58, p. 303-304, May/June 1966a.

GUENZI, W. D.; MCCALlA, T. M. Phytotoxic substances extract from soil. Soil Science Society of America Proceedings, Madison, v. 30, p. 214-216, 1966b.

GUENZI, W. D.; MCCALLA, T.; NORSTADT, F. A. Presence and persistence of phytotoxic substances in wheat, oat, corn, and sorghum residues. Agronomy Journal, Madison, v. 59, p. 163-164, Mar./Apr. 1967.

GUIMARÃES, R. J.; MENDES, A. N. G. Nutrição mineral do cafeeiro. Lavras: UFLA/FAEPE, 1998. 70 p.

LORENZI, H. Manual de identificação e controle de plantas daninhas: plantio direto e convencional. 4. ed. Nova Odessa: Plantarum, 2000. 383 p.

MATIELlO, J. B. O café: do cultivo ao consumo. São Paulo: Globo, 1991. 320 p.

PAVINATO, A.; AITA, C.; CERETA, C. A.; BEVILAQUA, G. P. Resíduos culturais de espécies de inverno e o rendimento de grãos de milho no sistema de cultivo mínimo. Pesquisa Agropecuária Brasileira Brasília, v. 29, n. 9, p. 427-432, set. 1994.

RAIJ, B. V. Fertilidade do solo e adubação. Piracicaba: Ceres, 1991.

RICE, E. L. Allelopathy. 2. ed. Orlando: Academic, 1984. $422 \mathrm{p}$.
SANTOS, C. C.; OLIVEIRA, D. F.; SOUZA, I. F.; ALVES, L. W. R.; FURTADO, D. A. S. Efeito de extratos orgânicos de plantas daninhas e cultivares de milho (Zea mays) na germinação e crescimento de plântulas de alface. In: CONGRESSO DA PÓS-GRADUAÇÃO DA UFLA, 10., 2001, Lavras. Anais... Lavras: APG, 2001. 1 CD-ROM.

SICKER, D.; SCHNEIDER, B.; HENNIG, L.; KNOP, M.; SCHULZ, M. Glycoside carbamates from benzoxazolin-2(3H)-one detoxification in extracts and exudates of corn roots. Phytochemistry, Oxford, v. 58, n. 5, p. 819-825, 2001.

SOUZA, I. F.; EINHELLIG, F. A. Potencial alelopático de 2-benzoxazolinona (BOA) e sua interação com atrazine no crescimento de plantas. Londrina, Planta Daninha, Rio de Janeiro, v. 12, n. 2, p. 84$86,1994$.

SOUZA, L. S.; FAVORETO, A. F.; FERRAZ, R. A.; VELINI, E. D. Efeitos alelopáticos de capim braquiária (Brachiaria decumbens) sobre três variedades de café (Coffea arabica). In: CONGRESSO BRASILEIRO DA CIÊNCIA DAS PLANTAS DANINHAS, 22., 2000, Foz do Iguaçu. Resumos... Londrina: SBCPD, 2000. p. 84.

SUZUKI, Y.; YAMAGUCHI, I.; YOKOTA, T.; TAKAHASHI, N. Identification of catasterone, typhasterol and teasterone from the pollen of Zea mays. Agricultural Biological Chemical, Tokyo, v. 50, n. 12, p. 3133-3138, 1986. 